\title{
Are men and women equal in front of depression? Theodore Hovaguimian
}

Address: University of Geneva, Switzerland

from International Society on Brain and Behaviour: 3rd International Congress on Brain and Behaviour

Thessaloniki, Greece. 28 November - 2 December 2007

Published: 17 April 2008

Annals of General Psychiatry 2008, 7(Suppl I):SI3 doi:I0.II86/I744-859X-7-SI-SI 3

This abstract is available from: http://www.annals-general-psychiatry.com/content/7/SI/SI3

(c) 2008 Hovaguimian; licensee BioMed Central Ltd.

The speech will examine the sex related differences in depressive disorders under several perspectives. The prevalence of depression to begin with, where factors underlying the female overrepresentation will be presented; then the differential access to health care, more restricted in males, will be discussed; next the gender specificities in clinical forms, suicidal behaviours and course of illness will be compared; and finally data suggesting distinctive responses to treatments, both pharmacological and psychotherapeutic, will be presented. 